\begin{tabular}{|c|c|}
\hline & $\begin{array}{l}\text { International Journal of Trend in Scientific } \\
\text { Research and Development (IJTSRD) }\end{array}$ \\
\hline 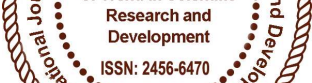 & International Open Access Journal \\
\hline 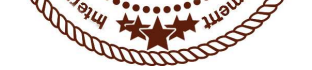 & ISSN No: 2456 - 6470 | www.ijtsrd.com | Volume - 2 | Issue - 2 \\
\hline
\end{tabular}

\title{
Social Support and Mental Health Status among Community Dwelling Elderly
}

\author{
Srisailamaiah Maheswara \\ Research Scholar, Centre for Research on Ageing, Department of Psychology, \\ Sri Venkateswara University, Tirupati, Andhra Pradesh, India
}

\section{ABSTRACT}

Ageing process is multi-disciplinary in nature, because it is a result of complex phenomena in connection with the physiological, psychological, and social. The problems of aged are manifold. Moreover these problems vary from individual to individual and culture to culture but there are certain common problems experienced by most of the aged person across culture and geographical location. These have been categorized as biological, social, economic and psychological problems. These problems are interdependent and interactive in nature the individual often doesn't know how to handle the situation and may end up with disturbed mental health. This study is an attempt to examine the social support and mental health status among community dwelling elderly of Ranga Reddy district of Telangana state. Mental health was assessed by using "Mental Health Inventory" by Jagadish and Srivastava (1983). Social support was assessed by using social support inventory by Jamuna.D \& Ramamurti (1991). For purposes of the present study, a total sample of 120 was taken out of which 60 were $(60+$ years) male and 60 were $(60+$ years $)$ female community dwelling elderly. Results reveals there was a significant difference in social support and mental health status among community dwelling elderly with respect to gender and locality, there were -0.59 negative correlations are seen between social support and mental health status among community dwelling elderly. The implications were drawn based on the findings.
Keywords: Mental Health, social support, Phenomena, Multi-disciplinary, Physiological, Manifold, Geographical location, Dwelling

\section{INTRODUCTION}

India is passing through technological, social, cultural and demographic transition. Consequently increase in awareness of health care among the people took place, which led to the improvement in the quality of health care facility which ultimately leads to the increase in elderly population. Along with the growing number of the aged, the traditional family support system is fast disappearing from the Indian society.

Ageing is the concluding period in human life span "move away" from earlier, more desirable period or time of "worth". The aging of humans is a physiological and self-motivated process ongoing with time. In accordance with most gerontologists' assertions it starts in the fourth decade of life and leads to death. The process of human old age is multifaceted and individualized, occurs in the biological, psychological and social sphere. Biological aging is characterized by progressive agechanges in metabolism and physicochemical properties of cells, leading to impair self-regulation, regeneration, and to structural changes and functional tissues and organs. It is a natural and irreversible process which can run as successful aging, typical or pathological. Biological changes that occur with age in the human body affect mood, attitude to the atmosphere, physical state and social activity, and 
designate the place of seniors in the family and society. Psychical ageing refers to human awareness and his adaptability to the ageing process. Among adaptation attitudes we can make a distinction: constructive, dependence, hostile towards others and towards self attitudes. With progressed age, difficulties with adjustment to the new situation are increasing, adverse changes in the cognitive and intellectual sphere take place, perception process involutes, perceived sensations and information received is lowered, and thinking processes change. Social ageing is limited to the role of an old person is culturally conditioned and may change as customs change. Social ageing refers to how a human being perceives the ageing process and how society sees it.

Old age is also associated with a number of psychological problems. These problems are either due to old age or as a result of interactive effect of social and economic problems. Affective disorders such as alterations in normal mood states, depressive reactions, elation and bodily preoccupation are the most common psychogenic illness found in old age. Certain psychosomatic symptoms, such as loss of appetite, sleeping difficulties and fatigue usually accompany affective disorders. Many people fear that senility is an inevitable curse of old age. Such persons have a limited ability to grasp abstractions, lack of ideas, think more slowly, unable to pay attention around them. Because of such mental deterioration, the aged may be unable to cope with such routine tasks as keeping clean and well groomed (Hamilton, 1994).

Van Hook and Ford (1998) present the results of a study involving mental health staff placed in rural health centre staff identified roles, benefiters and barriers to linkages. Benefits incorporated developed access and coordination and promotion of a more holistic sense of health care .Barriers were lack of space, dissimilarity among health disciplines and organizational problems. Social workers need good clinical and communication skills to work effectively in these programmes.

According to a regional survey, $71 \%$ of the elderly are living with their children (family care), $26.3 \%$ are living by themselves, including spousal care or self care and only $27.3 \%$ are in institutions (Jamuna \& Ramamurti, 2000).

Rodriguez, Zunzunegui \& Otero (2007) asses that the importance of social support on the health of the elderly Different forms of social support exist in facilities where the elderly live. It can be in the form of informal and formal support. Formal support was defined by Litwak (1985) as formal medical services, physician advice and other forms of help from health care personnel, while informal was defined as support given by family members, friends and other close associates. Social support can be in various forms. For this study, emphasis will be on the types of informal support and how it affects loneliness and depression.

Social support is a concept that is generally understood by intuitive sense, as the help from other people in a difficult life situation. One of the first definitions put forward by Cobb (1976), defined social support as the individual belief that one is cared for and loved, esteemed and valued, and belongs to a network of communication and mutual obligations. This concept is strategic in understanding the maintenance of health and the development of mental and somatic health problems, as well as their prevention.

Social support is "resources from the environment that can be beneficial to psychological that can be beneficial to psychological and physical health" according to the encyclopedia of psychology (Alan E. Kazclins Chiefed 1998).

\section{OBJECTIVES}

In the context of fore going observation a need was felt to analyze the influence of social support on mental health status of community dwelling elderly with the following objectives.

1. To assess the mental health status of male and female among community dwelling elderly.

2. To assess the mental health status among urban and rural areas of community dwelling elderly.

3. To measures the state of social support among male and female of community dwelling elderly.

4. To measures the state of social support among urban and rural areas of community dwelling elderly.

5. To test co-relation between social support and mental health status among community dwelling elderly. 


\section{HYPOTHESES}

Keeping the fore said objectives the following hypotheses were framed.

1. There would be significant differences in the mental health status among community dwelling elderly with respect to gender.

2. There would be significant differences in the mental health status among community dwelling elderly with respect to locality.

3. There would be significant differences in the social support among community dwelling elderly with respect to gender.

4. There would be significant differences in the social support among community dwelling elderly with respect to locality.

1. 5.There would be co-relation between social support and mental health status among community dwelling elderly.

\section{METHODOLOGY}

\section{Samples}

For purpose of the present study, a total sample of $\mathbf{1 2 0}$ was taken out of which 60 were (60+ years) male and 60 were $(60+$ years $)$ female community dwelling elderly of Ranga Reddy dist of Telangana State.

\section{Research Tools:}

1.Mental Health Inventory 'has been designed by Jagadesh, and A.Srivasthava (1983).

Mental Health Inventory consist of 56 items including 32 'false-keyed' and 24 'true-keyed' have been selected to constitute the format of the inventory. In this inventory, 4 alternative responses have been given to each statement, I.e.. Always, Often..........4 scores to Always,3 Scores to 'Often',2 Scores to 'Rarely', and 1 Score to 'Never' marked responses as to be assigned for true keyed(positive) statements where as 1.2.3. And 4 scores for Always,
Often, Rarely, and Never respectively in case of false keyed(negative) statements. The over lined items are negative while remaining positive. Lower score on the measure of mental health has been supposed to indicate high mental health where as higher score as the indicative of poor mental health.

2.Social Supports Inventory for the Elderly by Jamuna .D and Ramamurti, P.V. (1991).

This inventory had 35 items in the inventory and they were related to perception of social support. There are four areas with 5 statements each i.e emotional support, financial support, traditional, customs and legal support and social network or relationship. Each statement carries six points response scale varying from experience of good social support 'almost all the time' to 'no support'. Higher the score, better the perceived social support. Reliability of the inventory is 0.90 . It has a satisfactory context validity and temporal reliability.

\section{Procedure}

The study was conducted on male, female community dwelling elderly who are living in the urban and rural areas of Ranga Reddy dist of Telangana State. The entire process of fill the inventory was explained to them fully and clearly. The directions given on the questionnaire were explained to them. It was also made clear to them that their scores would be kept top secret. It was checked that none of the respondent left any questions unanswered.

\section{RESULTS AND DISCUSSION}

After collecting data from older people the scoring of the obtained data was done according to the manuals. Relevant statistical tests like mean, standard deviation " $t$ " test were applied and the Karl-person ' $r$ ' method used to check the correlation. The interpretations of the results obtained are as follows. 
International Journal of Trend in Scientific Research and Development (IJTSRD) ISSN: 2456-6470

Table1 : Showing the Mean, SD and " $t$ " value of Mental health status among male and female community dwelling elderly .

\begin{tabular}{|c|c|c|c|c|c|c|c|c|}
\hline \multicolumn{2}{|l|}{ Sex } & $\begin{array}{l}\text { Positive } \\
\text { self- } \\
\text { Evaluation } \\
\text { (PSE) }\end{array}$ & $\begin{array}{l}\text { Percep } \\
\text { tion of } \\
\text { Reality } \\
\text { (POR) }\end{array}$ & $\begin{array}{l}\text { Integrat } \\
\text { ion of } \\
\text { Persona } \\
\text { lity } \\
\text { (IOP) }\end{array}$ & $\begin{array}{l}\text { Autonomy } \\
\text { (AUTNY) }\end{array}$ & $\begin{array}{l}\text { Group } \\
\text { Oriented } \\
\text { Attitudes } \\
\text { (GOA) }\end{array}$ & $\begin{array}{l}\text { Environ } \\
\text { mental } \\
\text { Mastery } \\
\text { (EM) }\end{array}$ & $\begin{array}{l}\text { Total } \\
\text { Mental } \\
\text { Health } \\
\text { (TMH) }\end{array}$ \\
\hline \multirow[t]{3}{*}{ Male } & MEAN & 10.32 & 12.10 & 10.65 & 11.55 & 13.36 & 12.38 & 53.77 \\
\hline & SD & 6.25 & 0.03 & 3.18 & 5.42 & 3.35 & 3.15 & 32.02 \\
\hline & $\mathrm{N}$ & 60 & 60 & 60 & 60 & 60 & 60 & 60 \\
\hline \multirow[t]{3}{*}{ Female } & MEAN & 18.25 & 18.11 & 17.36 & 16.25 & 19.78 & 15.28 & 89.92 \\
\hline & SD & 6.32 & 1.58 & 3.25 & 3.15 & 4.15 & 2.55 & 32.15 \\
\hline & $\mathrm{N}$ & 60 & 60 & 60 & 60 & 60 & 60 & 60 \\
\hline \multicolumn{2}{|r|}{ t-value } & $3.95 * *$ & $7.56 * *$ & $6.32 * *$ & $3.25 * *$ & $3.32 * *$ & $6.22 * *$ & $4.34 * *$ \\
\hline
\end{tabular}

According to table 1 the results obtained on mental health status among the male and female community dwelling elderly. Male mean positive self evolution (PSE) score is 10.32 which is lower compared to female mean score 18.25 with the standard devotion 6.25 and 6.32 respectively. The $t-$ value is 3.95 , is significant at 0.01 level. Female elderly have poor mental health status than the male elderly in PSE dimension. Male mean Perception of Reality (POR) score is 12.11 which is lower compared to female mean score 18.11 with the standard devotion 0.03 and 1.58 respectively. The $t-$ value is 7.56 , is significant at 0.01 levels. Female elderly have poor mental health status than the male elderly in POR dimension. Male mean Integration of Personality (IOP) score is 10.65 which is lower compared to female mean score 17.35 with the standard devotion 3.18 and 3.25 respectively. The t- value is 6.32 , is significant at 0.01 level. Female elderly have poor mental health status than the male elderly in IOP dimension. Male mean Autonomy (AUTNY) score is 11.55 which is lower compared to female mean score 16.25 with the standard devotion 5.42 and 3.15 respectively. The t- value is 3.35 , is significant at 0.01 level. Female elderly have poor mental health status than the male elderly in AUTNY dimension. Male mean Group Oriented Attitudes (GOA) score is 13.36 which is lower compared to female mean score 19.78 with the standard devotion 3.35 and 4.15 respectively. The $t-$ value is 3.32 , is significant at 0.01 level. Female elderly have poor mental health status than the male elderly in GOA dimension. Male mean Environmental Mastery (EM) score is 12.28 which is lower compared to female mean score 15.28 with the standard devotion 3.15 and 2.55 respectively. The t- value is 6.22 , is significant at 0.01 level. Female elderly have poor mental health status than the male elderly in EM dimension. Male mean Total Mental Health (TMH) score is 53.77 which is lower compared to female mean score 89.92 with the standard devotion 32.02 and 32.15 respectively. The $t-$ value is 4.34 , is significant at 0.01 level. Female elderly have poor mental health status than the male elderly in TMH dimension. So we can say that the first hypotheses "There would be significant differences in the mental health status among community dwelling elderly with respect to gender" is accepted. 
International Journal of Trend in Scientific Research and Development (IJTSRD) ISSN: 2456-6470

Table 2: Showing the Mean, SD and " $t$ " value of Mental health status among urban and rural areas of community dwelling elderly .

\begin{tabular}{|c|c|c|c|c|c|c|c|c|}
\hline \multicolumn{2}{|l|}{ Locality } & $\begin{array}{l}\text { Positive } \\
\text { self- } \\
\text { Evaluation } \\
\text { (PSE) }\end{array}$ & $\begin{array}{l}\text { Perception } \\
\text { of Reality } \\
\text { (POR) }\end{array}$ & $\begin{array}{l}\text { Integration } \\
\text { of } \\
\text { Personality } \\
\text { (IOP) }\end{array}$ & $\begin{array}{l}\text { Autonomy } \\
\text { (AUTNY) }\end{array}$ & $\begin{array}{l}\text { Group } \\
\text { Oriented } \\
\text { Attitudes } \\
\text { (GOA) }\end{array}$ & $\begin{array}{l}\text { Environm } \\
\text { ental } \\
\text { Mastery } \\
\text { (EM) }\end{array}$ & $\begin{array}{l}\text { Total } \\
\text { Mental } \\
\text { Health } \\
\text { (TMH) }\end{array}$ \\
\hline \multirow[t]{3}{*}{ Urban } & MEAN & 15.62 & 12.25 & 17.62 & 13.22 & 15.33 & 14.35 & 85.33 \\
\hline & $\mathrm{SD}$ & 2.75 & 2.23 & 3.33 & 2.84 & 2.84 & 2.75 & 14.82 \\
\hline & $\mathrm{N}$ & 60 & 60 & 60 & 60 & 60 & 60 & 60 \\
\hline \multirow[t]{3}{*}{ Rural } & MEAN & 8.18 & 13.80 & 15.13 & 8.82 & 12.24 & 15.36 & 48.93 \\
\hline & SD & 7.45 & 2.78 & 3.39 & 2.36 & 4.25 & 2.65 & 25.36 \\
\hline & $\mathrm{N}$ & 60 & 60 & 60 & 60 & 60 & 60 & 60 \\
\hline \multicolumn{2}{|r|}{ t-value } & $6.23 * *$ & $2.33 * *$ & $3.22 * *$ & $6.26^{* *}$ & $6.05 * *$ & $1.82 * *$ & $12.52 * *$ \\
\hline
\end{tabular}

According to table 2 the results obtained on mental health status among the Urban and rural areas of community dwelling elderly. Urban mean positive self evolution (PSE) score is 15.25 which is higher compared to rural mean score 8.18 with the standard devotion 2.75 and 7.45 respectively. The t- value is 6.23 , is significant at 0.01 level. Urban elderly have poor mental health status than the rural elderly in PSE dimension. Urban mean Perception of Reality (POR) score is 12.25 which is lower compared to rural mean score 13.80 with the standard devotion 2.23 and 2.78 respectively. The $\mathrm{t}-$ value is 2.33 , is significant at 0.01 levels. Rural elderly have poor mental health status than the urban elderly in POR dimension. Urban mean Integration of Personality (IOP) score is 17.62 which is higher compared to rural mean score 17.315.13 with the standard devotion 3.33 and 3.39 respectively. The t- value is 3.32 , is significant at 0.01 level. Urban elderly have poor mental health status than the male elderly in IOP dimension. Urban mean Autonomy (AUTNY) score is 13.22 which is higher compared to rural mean score 8.82 with the standard devotion 2.84 and 2.36 respectively. The t- value is 6.26 , is significant at 0.01 level. Urban elderly have poor mental health status than the rural elderly in AUTNY dimension. Male mean Group Oriented Attitudes (GOA) score is 15.33 which is higher compared to rural mean score 12.24 with the standard devotion 2.84 and 4.25respectively. The $\mathrm{t}$ - value is 6.05 , is significant at 0.01 level. Urban elderly have poor mental health status than the rural elderly in GOA dimension. Urban mean Environmental Mastery (EM) score is 14.35 which is lower compared to rural mean score 15.36 with the standard devotion 2.75 and 2.65 respectively. The t- value is 1.82 , is significant at 0.01 level. Urban elderly have high mental health status than the rural elderly in EM dimension. Urban mean Total Mental Health (TMH) score is 85.33 which is higher compared to rural mean score 48.93 with the standard devotion 14.82 and 25.36 respectively. The tvalue is 12.58 , is significant at 0.01 level. Urban elderly have poor mental health status than the rural elderly in total mental health. So we can say that the second hypotheses "There would be significant differences in the mental health status among community dwelling elderly with respect to locality" is accepted.

\section{Table3 : Showing the Mean, SD and " $t$ " value of social support among male and female community dwelling elderly .}

\begin{tabular}{|c|c|c|c|c|c|}
\hline Gender & $\mathbf{N}$ & Mean & SD & "t? Value & Level of Significant \\
\hline Female & 60 & 183.20 & 14.35 & \multirow[t]{2}{*}{$3.4 * *$} & \multirow[t]{2}{*}{0.01} \\
\hline Male & 60 & 172.50 & 18.84 & & \\
\hline
\end{tabular}

According to table 3 the results obtained on of social support among male and female community dwelling elderly.Female mean score is 183.20 higher compare to male mean score 172.50 with the standard devotion 14.35 and 18.84 .The t- value is 3.4 is significant at 0.01 levels. Female elderly have highly social support than 
International Journal of Trend in Scientific Research and Development (IJTSRD) ISSN: 2456-6470

the male elderly .so we can say that the third hypotheses "There would be significant differences in the social support among community dwelling elderly with respect to gender." is accepted

Table 4 : Showing the Mean, SD and " $t$ " value of social support among urban and rural areas of community dwelling elderly .

\begin{tabular}{|c|c|c|c|c|c|}
\hline Locality & N & Mean & SD & " t" Value $^{\text {' }}$ Level of Significant \\
\hline Rural & 60 & $\mathbf{5 9 . 9 7}$ & 5.99 & 20.32 & 0.01 \\
\hline Urban & 60 & 48.12 & $\mathbf{4 . 1 2}$ & & \\
\hline
\end{tabular}

According to table 4 the results obtained on of social support among urban and rural community dwelling elderly .rural mean score is 59.97 higher compare to urban mean score 48.12 with the standard devotion 5.99 and 4.12 .The $\mathrm{t}-$ value is 20.32 is significant at 0.01 levels. Rural elderly have highly social support than the urban elderly so we can say that the forth hypotheses "There would be significant differences in the social support among community dwelling elderly with respect to locality." is accepted

Table 5: Showing the correlation between social
support and mental health status
\begin{tabular}{|l|c|c|}
\hline Variables & N & r \\
\hline Social Support & & -0.59 \\
\hline Mental Health & 120 & \\
\hline
\end{tabular}

According to table 5 the results shows that negative correlation between social support and mental health status. The -0.59 negative correlation between social support and mental health status. It means that as the social support increases the mental health status will decreases and when social support decreases the mental health well being increases, so that we can say there is a relationship between social support and mental health status, high social support low mental health status and low social support high mental health status among community dwelling elderly. Then the hypothesis "There would be co-relation between social support and mental health status among community dwelling elderly." is accepted.

\section{Conclusion}

There was a significant difference in social support and mental health status among community dwelling elderly with respect to gender and locality, there were -0.59 negative correlations are seen between social support and mental health status among community dwelling elderly, it shows that the high social support elderly people have poor mental health status and low social support elderly have high mental health status among community dwelling elderly .

\section{Suggestions}

Endeavour can be executed to analyze more than 120 data of sample with efficacy to attain better results. For the accumulation of information, variegated methods except questionnaires can be adopted selection of sample can be accomplished with the intake of different peoples from different state and district to ascertain their social support and mental health status among community dwelling elderly. To crown the edifice of the research work, other method of selecting sample can be appropriated.

\section{REFERENCE}

1) Alan Ir E.Kazdin (1998). Encyclopedia of psychology, Oxford University Press. Volume7, 247-250, 373.

2) Cobb, S. (1976). Social support as a moderator of life stress. Psychometric Medicine, 38, 300-314.

3) Conner, K. O., Copeland, V. C., Grote, N. K., Koeske, G., Rosen, D., Reynolds, C. F., \& Hamilton, I. S. (1994). The psychology of aging: An introduction.( $2^{\text {nd }}$ ed.). Pennsylvania Jessica Kingsley.

4) Jamuna, D. \& Ramamurti, P.V. (2000). Burnout among the Caregivers of disabled Elderly: Effect of Intervention. Psychological Studies, 45(3), 150155.

5) Ramamurti, P.V. and Jamuna, D. (1991). Social Supports Inventory for the Elderly, Journal of Psychological Researches, Vol. 35, 133-136.

6) Rodriguez-Laso, A., Zunzunegui, V. M., \& Otero, A. (2007). The effects of social relationships on survival in elderly residents of a southern European community: A cohort study. BMC Geriatrics, 7, 19-26.

7) Van Hook, M. P., \& Ford, M. E. (1998). The linkage model for delivering mental health services in rural communities: Benefits and challenges. Health \& Social Work, 23(1), 53-60. 